\title{
A method for evaluating the effects of allograft sterilization procedures on the viability of human fibroblasts
}

\author{
S. C.W. CH A L C R O F T, J . B. G A V I N, \\ a n d R. N. SE E L Y E \\ Department of Pathology, University of Auckland, Auckland, New Zealand
}

\begin{abstract}
Chalcroft, S. C. W., Gavin, J. B., and Seelye, R. N. (1974). Thorax, 29, 539-544. A method for evaluating the effects of allograft sterilization procedures on the viability of human fibroblasts. A semiquantitative method for assessing the effects of allograft sterilization procedures on the viability of cultured human fibroblasts is described. The proportions of 'viable', 'altered', and 'non-viable' cells in four groups of fibroblasts on coverslips were estimated using light microscopy and their staining reactions with neutral red and nigrosin. While a control group of fibroblasts remained viable, exposure for one to three weeks to each of three solutions used in allograft preparation produced a progressive transition first to the altered and then to the non-viable category. These findings were confirmed by electron microscopic examination of similarly treated cells grown on millipore filters. Applications of the method are discussed.
\end{abstract}

Because of difficulties in the supply and banking of uncontaminated human heart valves, those which are used as allografts are often stored in various combinations and concentrations of antibiotics. It has been claimed that if the viability of the donor fibroblasts is maintained during these procedures the duration and function of the allograft are much improved (Al-Janabi, GonzalezLavin, Neirotti, and Ross, 1972; Lockey, AlJanabi, Gonzalez-Lavin, and Ross, 1972) presumably by virtue of their continued function and survival within the recipient (Angell, Shumway, and Kosek, 1972).

This paper describes a relatively simple, semiquantitative method for assessing the effects of different treatment procedures on the viability of cultured human fibroblasts.

\section{MATERIAL AND METHODS}

Diploid fibroblasts derived from human muscle and grown in culture were obtained from the Virology Laboratory at Auckland Public Hospital. These were subcultured at $37^{\circ} \mathrm{C}$, either on $22 \mathrm{~mm} \times 6 \mathrm{~mm}$ glass coverslips or on autoclaved strips of $0.22 \mu \mathrm{m}$ pore size filter (MF-millipore GSWP, Millipore Corp., Bedford, Mass., USA) of similar size, in sealed glass tubes containing Eagle's basal medium (Grand Island Biological
Co., New York, USA) to each $100 \mathrm{ml}$ of which had been added $10 \mathrm{ml}$ fetal calf serum (Commonwealth Serum Laboratories, Melbourne, Australia), $1 \mathrm{ml}$ of $4.4 \%$ sodium bicarbonate, $10 \mathrm{mg}$ of kanamycin, and 10,000 units of penicillin.

After three days these were allotted to four groups each consisting of six coverslips and three millipore filter strips and the groups were then treated as follows:

GROUP A Fibroblasts in this control group were maintained, as before, at $37^{\circ} \mathrm{C}$ in supplemented Eagle's basal medium which was changed twice weekly.

GROUP B Fibroblasts were placed into Hanks's balanced salt solution (Hanks, 1948) at $4^{\circ} \mathrm{C}$. This was the solution which was used for the so-called 'fresh' allografts inserted at Greenlane Hospital in 1963 (Barratt-Boyes et al., 1969).

GROUP C Fibroblasts were placed in Hanks's balanced salt solution containing 50 units of penicillin, $1 \mathrm{mg}$ of streptomycin, $1 \mathrm{mg}$ of kanamycin, and $25 \mu \mathrm{g}$ of amphotericin B in each millilitre of solution. After four days this solution was renewed. After another four days it was replaced with Hanks's balanced salt solution alone. All procedures were carried out at $4^{\circ} \mathrm{C}$. This was the method of heart valve sterilization 
in use at Greenlane Hospital from 1968 to 1972 (Barratt-Boyes and Roche, 1969).

GROUP D Fibroblasts were placed in tissue culture medium 199 (Commonwealth Serum Laboratories, Melbourne, Australia) to which was added the same concentration of antibiotics used in group B, plus phenol red indicator. This solution was renewed after four days, and after a further four days it was replaced with medium 199 without antibiotics to which was added $10 \%$ fetal calf serum. All procedures were carried out at $4^{\circ} \mathrm{C}$. This is the method of heart valve sterilization currently in use at Greenlane Hospital.

After intervals of one, two, and three weeks respectively, coverslips and millipore filters were taken from each group and were treated as follows:

One coverslip was washed briefly in Hanks's balanced salt solution then incubated for 15 minutes $\left(37^{\circ} \mathrm{C}\right)$ in a $0.0025 \%$ solution of neutral red (Colour Index 50420, George T. Gurr, Searle Scientific Services, High Wycombe, Bucks, England) in normal saline ( $\mathrm{pH}$ 7.2) prepared according to Sawicki, Kieler, and Briand (1967). A second coverslip was incubated for 5 minutes $\left(37^{\circ} \mathrm{C}\right)$ in a $0.01 \%(w / v)$ solution of nigrosin (Colour Index 50040, George T. Gurr, Searle Scientific Services, High Wycombe, Bucks, England) in normal saline ( $\mathrm{pH} 7 \cdot 2)$ prepared according to Kaltenbach, Kaltenbach, and Lyons (1958).

The coverslips were then rinsed in Hanks's balanced salt solution and placed on glass slides for light microscopic examination. The proportions of stained and unstained cells were then calculated for representative photomicrographs of each preparation.

The millipore filters were briefly rinsed in Hanks's balanced salt solution and immersed in phosphatebuffered ( $\mathrm{pH} 7.4$ ) $5 \%$ glutaraldehyde for four hours at $4^{\circ} \mathrm{C}$. After being washed in sucrose-phosphate buffer (pH 7.4) and postfixation for one hour in $1 \%$ osmium tetroxide solution they were dehydrated with graded ethanol. They were then orientated and embedded in epoxy resin following the method of Dalen and Nevalainen (1968). Sections $50-100 \mathrm{~nm}$ thick of cell-rich areas were stained with uranium and lead salts and examined with a Philips EM 300 electron microscope.
RESULTS

All coverslips showed a profuse growth of cells. $\frac{\overline{\bar{s}}}{3}$ In the control group (group A) all cells were typically spindle-shaped and each had an ovoid cen-ov trally placed nucleus (Fig. 1). Virtually all of theses cells stained with neutral red and very few incor- $?$ porated nigrosin (Table).

However, in all other groups (groups B, C, ando D) few cells stained with neutral red but many incorporated nigrosin (Fig. 2). The proportions of neutral red and nigrosin-stained cells were seldom complementary, indicating that some cells stainedy neither with neutral red nor nigrosin (Table). $\omega$ The proportion of nigrosin-stained cells varied from group to group but progressively increasedin all three groups from the first to the third week $\$$ (Table). Most nigrosin-positive cells also had rounded, rather than an elongated form (Fig. 2) $\stackrel{\mathbb{D}}{3}$

After one week in TC199 medium plus antibi- 유 otics almost no cells showed nigrosin staining but overall the lowest proportions of nigrosin-positive cells were observed among those exposed to ${ }^{f}$ Hanks's balanced salt solution plus antibiotics (Table).

The growth of cells on millipore filters was no as profuse as on glass, perhaps because their con tinued growth tended to produce a localized $B$ clumping rather than a layering of cells. Electron microscopy confirmed the elongated form of the untreated cells (group A) which lay in close con tact with the underlying millipore filter and with neighbouring cells. They had a continuous celf membrane and contained nuclei, mitochondria은 rough and smooth-surfaced endoplasmic reti culum, and rounded electron-dense inclusions (Fig. 3). In contrast, many cells in the other three groups showed degenerative changes by the end of one week. Affected cells were rounded and contained irregular clumps of nuclear material음 membrane fragments, intact and degenerate mitochondria, vesicles, lipid droplets, ant.

T A B L E

CELL STAINING AND MORPHOLOGY IN THE VARIOUS EXPERIMENTAL GROUPS

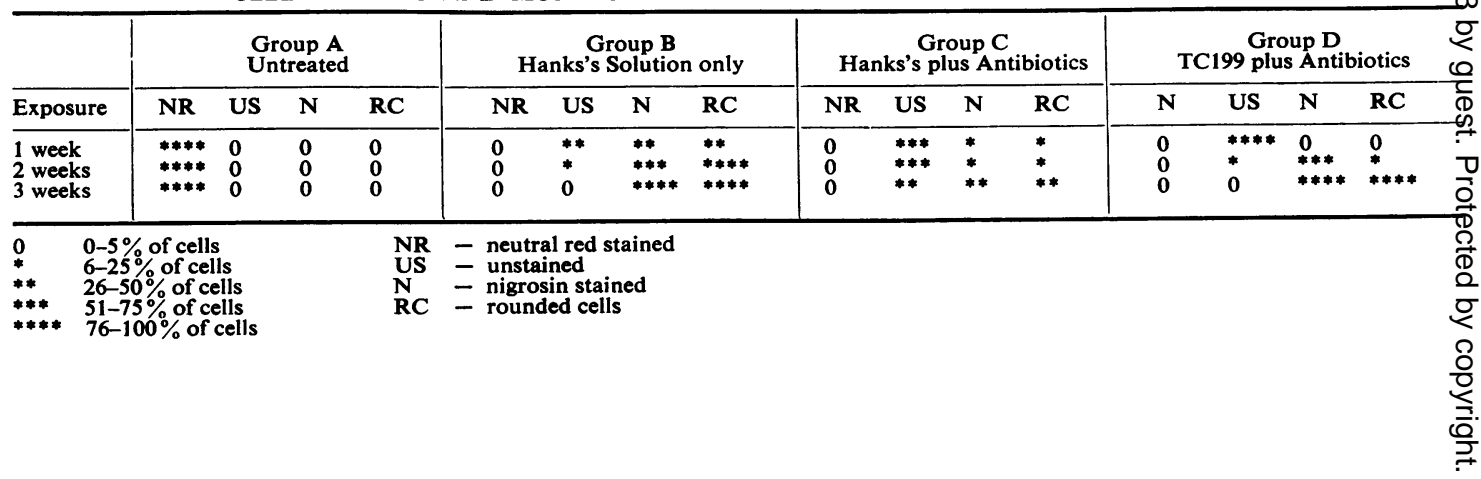




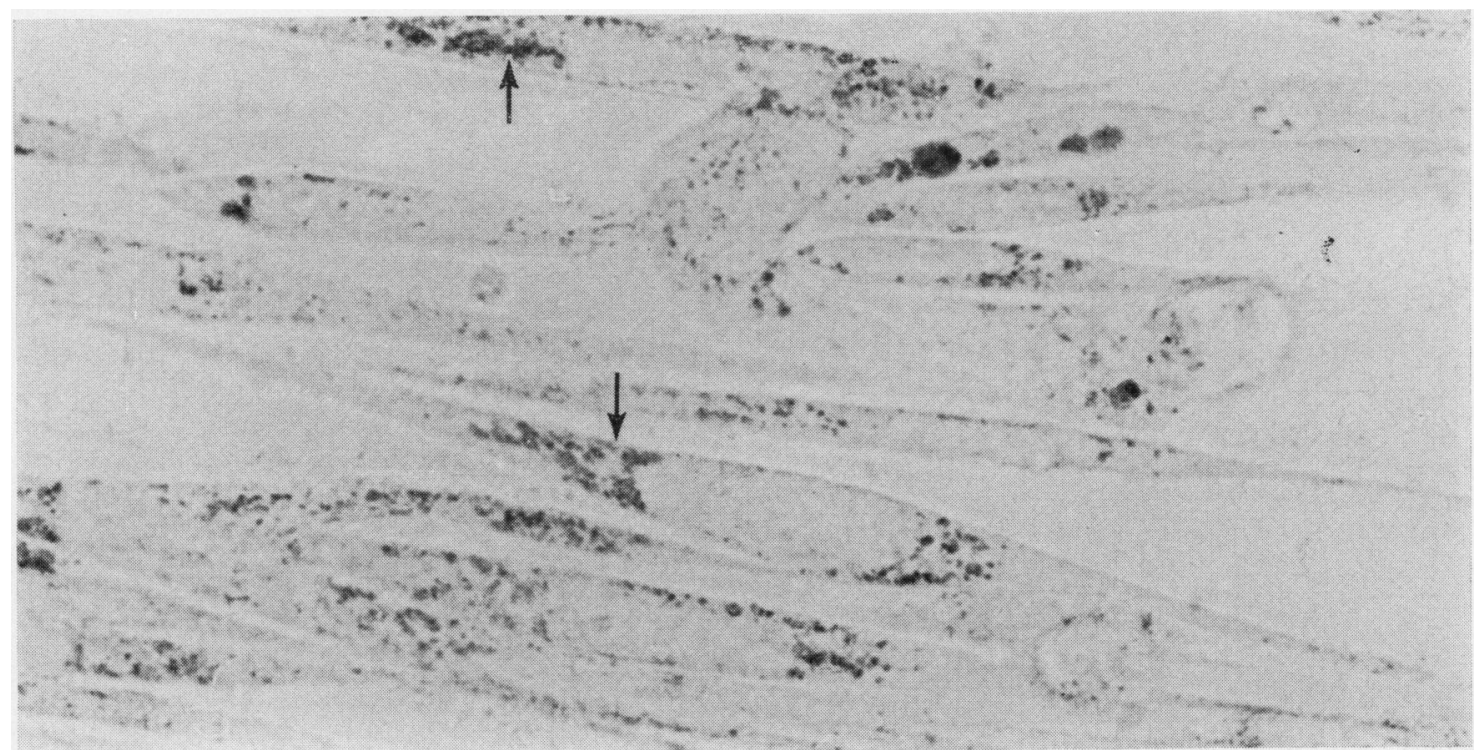

FIG. 1. Elongated control fibroblasts (group A) which contain granular, intracytoplasmic accumulations (arrows) of neutral red stain. Oil immersion $\times 3,500$.

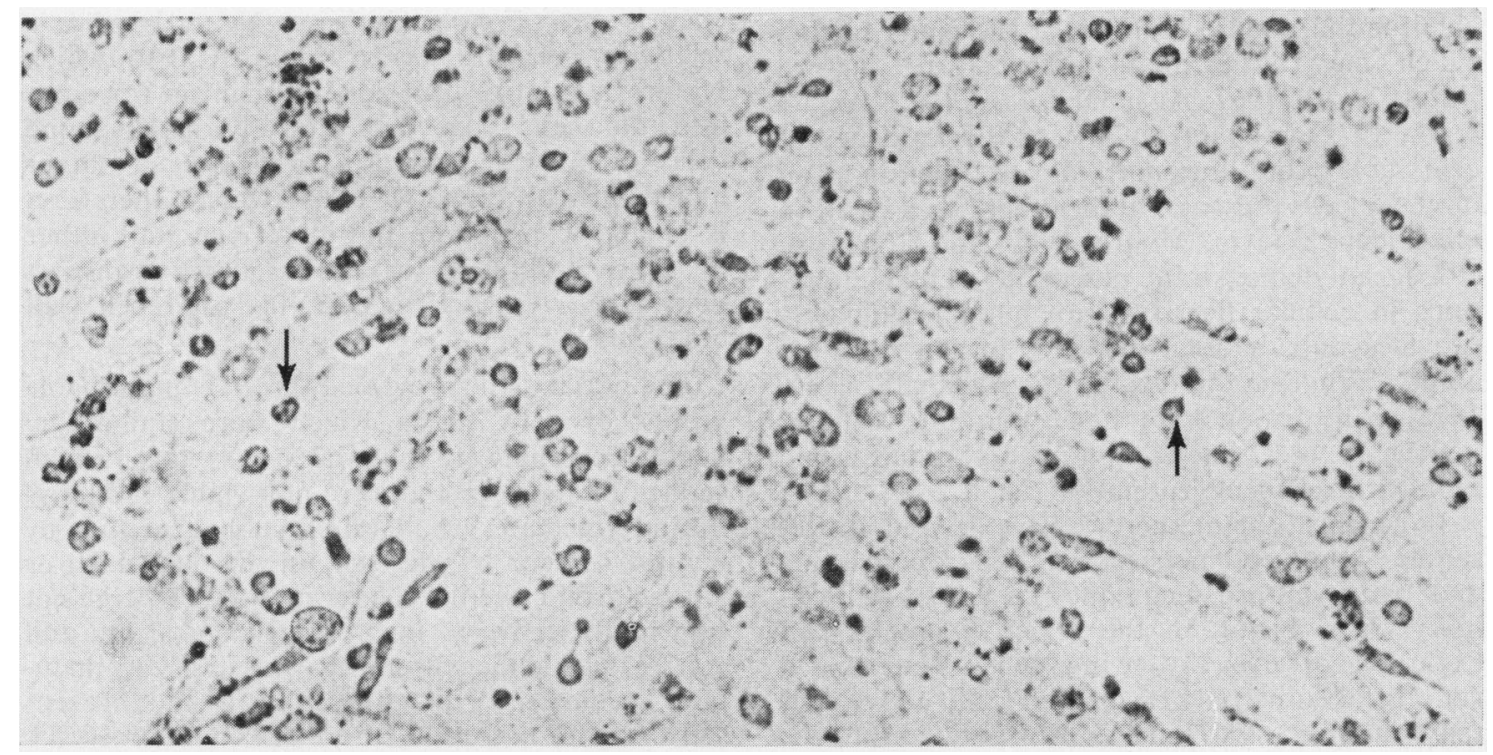

FIG. 2. Fibroblasts after three weeks' exposure to Hanks's solution plus antibiotics (group C). The majority have a rounded form (arrows) and have stained with nigrosin. $\times 250$. 


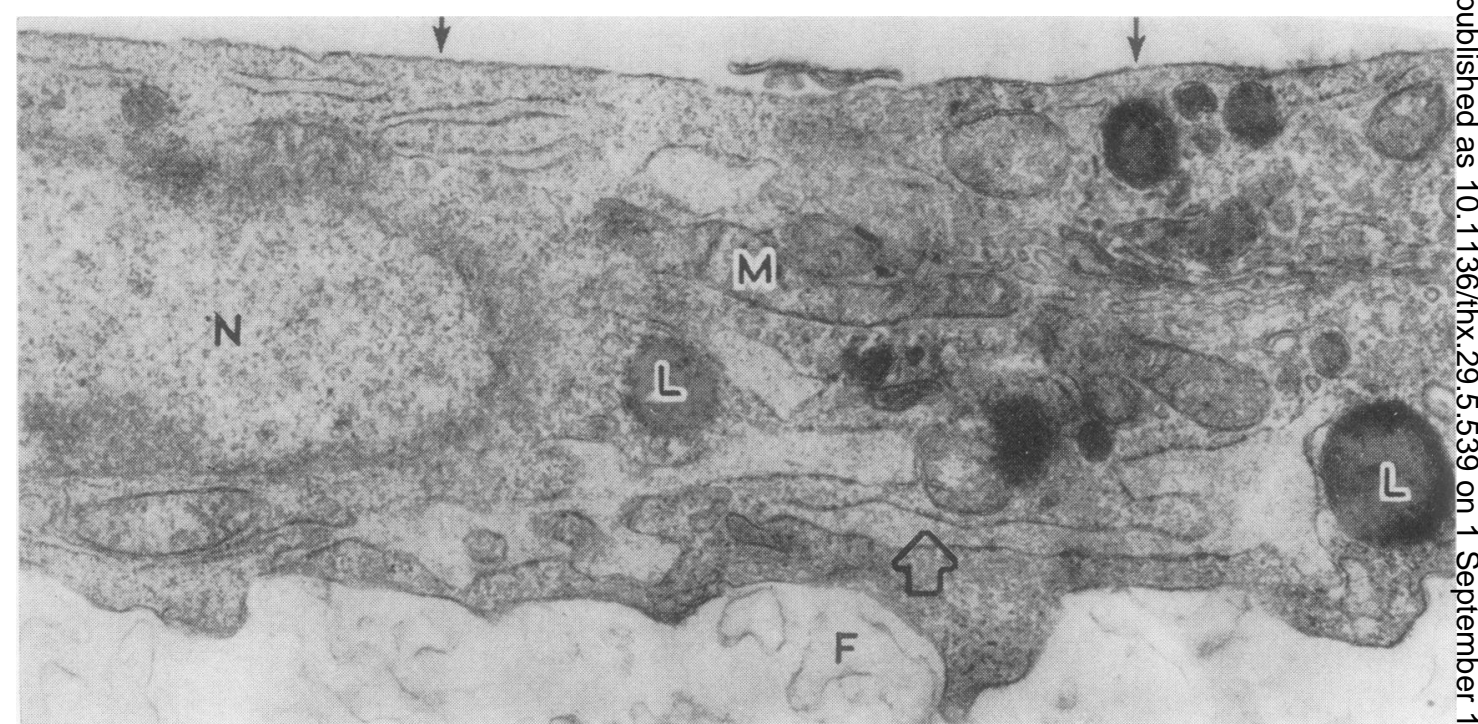

FIG. 3. Part of a control fibroblast on millipore filter $(F)$. It contains a nucleus $(N)$, mitochondria $(M)$, endoplasmie reticulum (large arrow), and lipid droplets $(L)$. The cell membrane is intact (small arrows). EM $\times 11,500$.

remnants of cytoplasmic matrix (Fig. 4). After three weeks virtually all cells showed these signs of degeneration.

\section{DISCUSSION}

Investigations of the viability of fibroblasts in heart valve allografts have so far employed involved and sophisticated methods which are unsuitable for the rapid evaluation of the many factors which may affect these cells. Tissue culture (Mohri et al., 1967; Al-Janabi et al., 1972; Angell et al., 1972) undoubtedly gives direct evidence of cell viability but does not indicate the proportion of viable cells present. On the other hand, electron microscopy (Gavin, Monro, Wall, and Chalcroft, 1973) can demonstrate potentially lethal alterations in cellular fine-structure but unfortunately provides only indirect evidence of fibroblast viability. While autoradiography (Al-Janabi et al., 1972) can demonstrate and quantitate cellular activity, it is a time-consuming technique which requires careful interpretation.

In contrast, the method we have devised utilizes simple, relatively inexpensive, light microscopic and tissue culture techniques to assess cell viability. It is based on the selective uptake and exclusion of dyes by living cells. Neutral red stain is taken up only by metabolically active cells (Sawicki et al., 1967) and is incorporated into the lipochondria and lysosomes within their cytoplasm (Lane, 1968; Morgan, 1968). The action of nigro- $\sin$ is less well defined, but Kaltenbach et als (1958) suggest that the extent of cellular staining is inversely related to the activities of thos. energy-dependent enzyme systems which are con $\stackrel{\bar{Q}}{\square}$ cerned with the integrity and semi-permeability of the cell membrane. Both of these stains belong to the same class of basic dyes, the azin subgroup of the quinone-immine dyes. Their major differ? ence is one of molecular size. Neutral red is relatively small molecule (mol. wt 289) whiclp requires an active transport mechanism for entræ into the cell since only actively metabolizing cells stain, while nigrosin is a dye of large? molecular size (mol. wt 1065) which, thereforeo is unable to penetrate the intact cell wall either by passive diffusion or by an active transpor? mechanism. Entry is gained only after cell walt breakdown.

The present study revealed three distinguishablô groups of cells, those which were stained bu neutral red and were thus viable cells, those which stained by nigrosin and were non-viable cells, an f $^{2}$ the intermediate group which stained neither by neutral red nor by nigrosin. In this unstained of altered group, the fibroblasts presumably were no: sufficiently active to incorporate neutral red and yet retained sufficient enzymatic activity to main $\bar{\sigma}^{-}$ tain the integrity of the cell wall and prevent the entry of nigrosin. Our electron microscopi observations, together with the progressive alteration in the proportion of cells in these three 


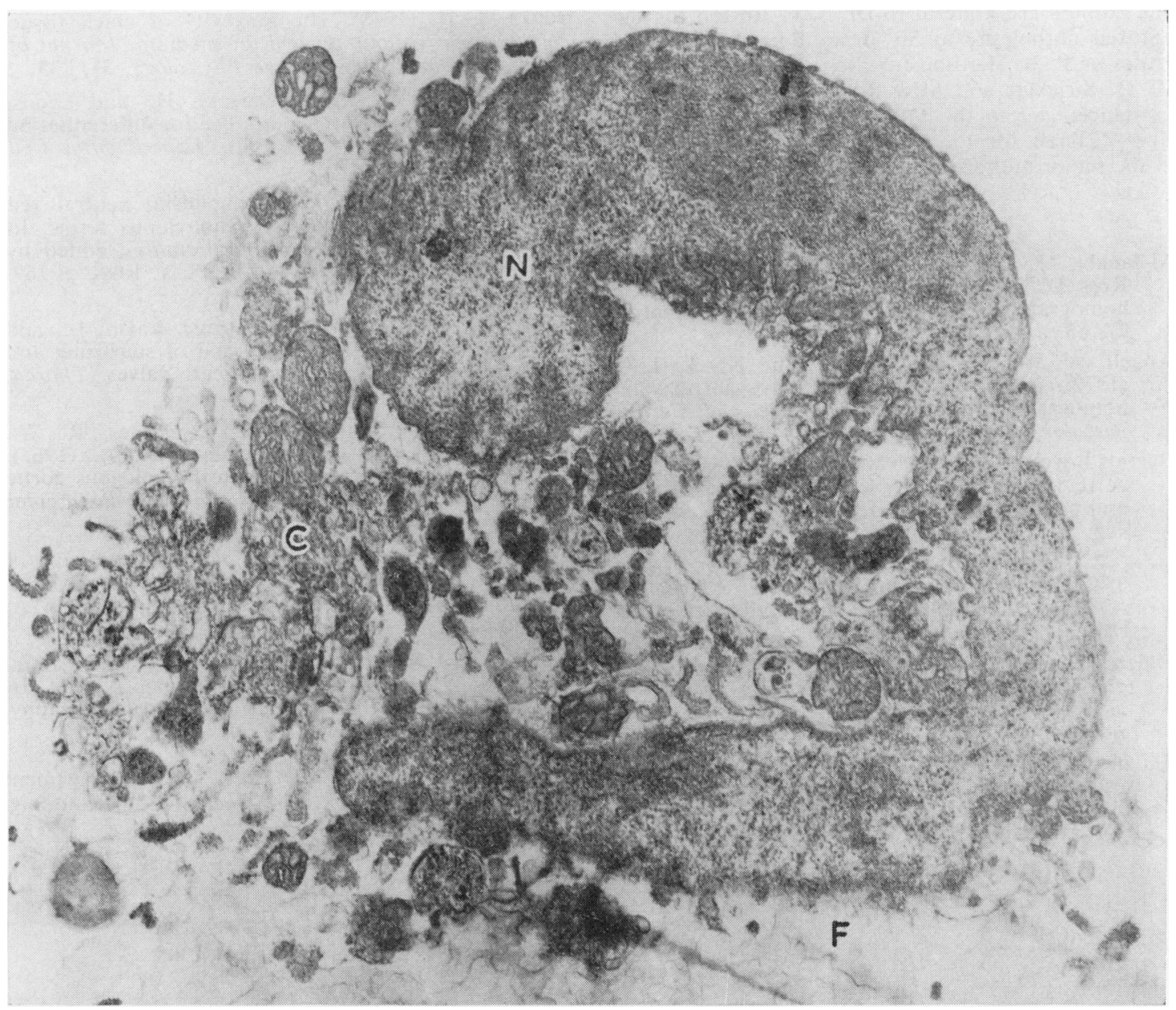

FIG. 4. Rounded-up remnants of a fibroblast on millipore filter $(F)$ after three weeks' exposure to tissue culture medium and antibiotics (group D). It consists of nuclear remnants $(N)$ and cytoplasmic debris $(C)$ but lacks a cell membrane. $E M \times 9,600$.

categories in all but the control group, indicates a transition from 'viable' to 'altered' to 'non-viable' cells.

As this study was designed to evaluate this method, our preliminary findings cannot be used to draw any definite conclusions about the treatment procedures used. However, several interesting points emerged.

All those fibroblasts which were stored at $4^{\circ} \mathrm{C}$ lost their capacity to incorporate neutral red within seven days. Since this change was not prevented by the substitution of a tissue culture medium for Hanks's balanced salt solution we suspect that it was not due to the absence of cell nutrients. It seems more likely to be due to the effects of low temperatures on their metabolic activities. While antibiotics in sufficient concentration to kill microbial cells also may be expected to affect tissue cells, the death of cells we observed in the antibiotic-containing media was unlikely to be due to penicillin since the control group were maintained in a medium which contained much higher concentrations of this antibiotic.

Obviously, many factors including temperature, osmotic pressure, $\mathrm{pH}$, and availability of nutrients, as well as the choice and concentrations of antibiotics, may affect the cells of heart valves prepared as allografts. The method we describe could be used with advantage to evaluate their effects on fibroblast viability. 
The authors are grateful to Dr. J. F. Burton for the cultured fibroblasts, to Sir Brian Barratt-Boyes and Professor P. B. Herdson for their comments, to Miss M. G. Strickett and Miss R. M. Griffiths for their assistance, and to the Medical Research Council of New Zealand for the summer studentship awarded to the senior author.

\section{REFERENCES}

Al-Janabi, N., Gonzalez-Lavin, L., Neirotti, R., and Ross, D. N. (1972). Viability of fresh aortic valve homografts: a quantitative assessment. Thorax, 27, 83.

Angell, W. W., Shumway, N. E., and Kosek, J. C. (1972). A five-year study of viable aortic valve homografts. Journal of Thoracic and Cardiovascular Surgery, 64, 329.

Barratt-Boyes, B. G. and Roche, A. H. G. (1969). A review of aortic valve homografts over a six and one-half year period. Annals of Surgery, 170, 483.

_, - B Brandt, P. W. T., Smith, J. C., and Lowe, J. B. (1969). Aortic homograft valve replacement. A long term follow-up of an initial series of 101 patients. Circulation, 40, 763.

Dalen, H. and Nevalainen, T. J. (1968). Direct epoxy embedding for vertical sectioning of cells grown as a monolayer on millipore filter. Stain Technology, 43, 217.

Gavin, J. B., Monro, J. C., Wall, F. M., and Chalcroft, S. C. W. (1973). Fine structural changes in the fibroblasts of canine heart valves prepared for grafting. Thorax, 28, 748.
Hanks, J. H. (1948). The longevity of chick tissue cultures without renewal of medium. Journal of Cellular and Comparative Physiology, 31, 235.

Kaltenbach, J. P., Kaltenbach, M. H., and Lyons, $\stackrel{\mathbb{\Omega}}{\varrho}$ W. B. (1958). Nigrosin as a dye for differentiating live and dead ascites cells. Experimental Cell Research, 15, 112.

Lane, Nancy J. (1968). Lipochondria, neutral red $\stackrel{\vec{\rightleftarrows}}{\vec{\partial}}$ granules and lysosomes: synonymous terms. In $\vec{\omega}$ Cell Structure and its Interpretation, edited by S. M. McGee-Russell and K. F. A. Ross, p. 169. Edward Arnold, London.

Lockey, E., Al-Janabi, N., Gonzalez-Lavin, L., and of Ross, D. N. (1972). A method of sterilizing and of preserving fresh allograft heart valves. Thorax, $\underset{\mathcal{O}}{ }$ 27, 398.

Mohri, H., Reichenbach, D. D., Barnes, R. W.. Nelson, R. J., and Merendino, K. A. (1967). is Studies of antigenicity of the homologous aortic $\mathbb{D}$ valve. Journal of Thoracic and Cardiovascular $\frac{\vec{D}}{\mathrm{D}}$ Surgery, 54, 564.

Morgan, W. S. (1968). The biological activity of $\underset{\Phi}{ }$ neutral red. In Cell Structure and its Interpretation, edited by S. M. McGee-Russell and K. F. A. Ross, p. 79. Edward Arnold, London.

Sawicki. W., Kieler, J., and Briand, P. (1967). VitalO staining with neutral red and trypan blue of ${ }^{3} \mathrm{H}-O$ thymidine-labelled cells prior to autoradiography. Stain Technology, 42, 143.

Requests for reprints to: Dr. J. B. Gavin, Department $\stackrel{\stackrel{2}{\mathrm{D}}}{\Omega}$ of Pathology, University of Auckland, Private Bag. $\vec{F}$ Auckland, New Zealand. 